\title{
QUALIDADE, ENQUADRAMENTO E LIMITAÇÕES DE USO DAS ÁGUAS SUPERFICIAIS DA LAGOA MAIOR 2011 e 2012 EM TRÊS LAGOAS - MS
}

\author{
Denivaldo Ferreira de Souza ${ }^{1}$
}

André Luiz Pinto²

\begin{abstract}
Alyson Marcelo Savio Mendes ${ }^{3}$
Resumo: O Conselho Nacional do Meio Ambiente - CONAMA normatizou através das resoluções 357 de 2005, o enquadramento das limitações de uso de corpos hídricos perante os padrões de qualidade. A água não deve somente ser considerada um bem natural indispensável à sobrevivência dos seres vivos, mas, pelo seu valor político, econômico e social. Perante a importância da água para a humanidade e que segundo Tundisi (1999) uma sociedade pode ser qualificada pelos cuidados que tem por suas águas, o presente trabalho analisou a qualidade da maior lagoa urbana da cidade de Três Lagoas, que constitui o seu principal atrativo turístico. Contudo, enfatizou-se história, geologia, clima, hidrografia, legislação, e etc, da região de Três Lagoas e da área de estudo, a Lagoa Maior. Para isso, os parâmetros mensurados foram de oxigênio dissolvido, potencial hidrogeniônico, turbidez, condutividade elétrica, temperaturas do ar e da água. No entanto, foram coletadas amostras em treze estações ao redor da Lagoa Maior, os quais localizam-se em pontos estratégicos, tais como: saídas de caixas de retenção de água pluvial, afloramento de água subterrânea e ladrões de controle de nível da água da lagoa. Os resultados enquadram a lagoa, em sua maioria, nas classes III e IV, que preconiza seu uso apenas para navegação e à harmonia paisagística.
\end{abstract}

Palavras-chave: Qualidade de água; Lagoa Maior; Três Lagoas.

1. Geógrafo pela Universidade Federal de Mato Grosso do Sul, campus Três Lagoas - MS. deny1609@gmail.com 2. Pesquisador doutor pela Universidade Federal de Mato Grosso do Sul, campus Três Lagoas - MS. andre.pinto@ufms.br

3. Graduando em Geografia pela Universidade Federal de Mato Grosso do Sul, campus Três Lagoas - MS. alys tha@hotmail.com 


\section{INTRODUÇÂO}

A ciência ao longo de inúmeras descobertas induz que a vida nasceu da água e é mediante a ela que mantivemos nossa sobrevivência. O nosso planeta possui $70 \%$ da superfície de água, dessa reserva mundial $97,2 \%$ é constituída pela água dos oceanos e mares e 2,15\% pela água contida nos "glaciers" e "icebergs" polares. Os 0,65\% restantes, que estão distribuídos entre a terra e a atmosfera, representam oito milhões e quinhentos mil $\mathrm{km}^{3}$ de água (constituem o volume de todos os rios e lagos do mundo de toda a água subterrânea, da umidade contida no solo e do vapor d'água presente na atmosfera). Desses oito milhões e quinhentos mil $\mathrm{Km}^{3}, 48 \%$ são águas subterrâneas até oitocentos metros de profundidade, $49 \%$ abaixo de oitocentos metros de profundidade, 1,5\% estão em rios, lagos, lagoas e cursos d'água, $0,8 \%$ na umidade do solo e $0,7 \%$ no vapor d'água na atmosfera (MOITTA e CUDO, 1991).

O Brasil embora possa considerar-se privilegiado em relação a outros países, convive com alguns problemas. A bacia Amazônica concentra $70 \%$ da água superficial do país, para atender a $7 \%$ da população. Os restantes $93 \%$ de brasileiros compartilham $30 \%$ da água. Na Região Sudeste, onde moram $42 \%$ dos brasileiros estão localizados $6 \%$ da água. Em reservas de água potável o Brasil é dotado dessa fonte, possui 2,82\% da população mundial e $11,6 \%$ de toda a água doce superficial do mundo.

Contudo, a água pode ser considerada um recurso abundante, relativamente para as necessidades atuais. No passado era visto como bem infinito, mas os tempos mudaram e a água é hoje o recurso mais importante para vida, e é caracterizado em sua pureza e pelo descaso como finito para o consumo humano. Moitta e Cudo (1991) relatam que a escassez é muito mais grave em regiões onde o desenvolvimento se processou de forma desordenada. Isso é visto nos grandes centros urbanos onde a contaminação das águas disponíveis para o consumo acontece pelos lançamentos indiscriminados de esgotos domésticos, despejos industriais e outros poluentes, e no campo em crescimento econômico utilizando enormes volumes de água para irrigação e poluindo com diversos agrotóxicos.

A qualidade das águas, a partir da Primeira Revolução Industrial, está totalmente relacionada com as interferências antrópicas, e o seu estudo é fundamental para a avaliação da balneabilidade de uso. Para Tundisi (1999), alterações na qualidade, distribuição e quantidade de água podem ameaçar a sobrevivência dos seres vivos. Em vista disso, com certas análises podemos classificar a adequação das águas para o consumo humano, recreação, indústria e agricultura. 
Com o aumento da poluição em ambientes aquáticos algo deve ser feito. Portanto, o objetivo destas análises é avaliar a qualidade das águas superficiais da maior lagoa urbana presente em de Três Lagoas, conhecida como Lagoa Maior. Lagoa que no passado abasteceu a cidade e constitui o seu principal atrativo turístico. Foram utilizados como indicador principal o oxigênio dissolvido e os parâmetros coadjuvantes de turbidez, potencial hidrogeniônico, condutividade elétrica, temperatura da água e do ar. Parâmetros estes de fácil coleta em campo e de baixo custo, possibilitando informações confiáveis, passíveis de enquadrar a Lagoa nas classes de limitações de uso do Conselho Nacional do Meio Ambiente, resolução 357 de 2005. Assim, o presente estudo de caso destaca a análise da qualidade da água da Lagoa Maior, visando subsidiar ações e/ou estudos que visem contribuir para o ordenamento e gestão desse importante recurso hídrico do município.

As metas essenciais deste estudo de caso irão enquadrar e limitar a qualidade das águas superficiais da Lagoa Maior Urbana de Três Lagoas, para proporcionar a sociedade:

$\checkmark$ As diferentes classificações que os recursos hídricos, em pauta as água superficiais, recebem de um órgão responsável, no caso, o Conselho Nacional do Meio Ambiente CONAMA, uma das instituições mais respeitada no assunto;

$\checkmark$ Compreensão das formas de análises, parâmetros e os métodos utilizados;

$\checkmark$ Enquadramento dos pontos monitorados e da lagoa como um todo; e

$\checkmark$ Subsidiar novos estudos e/ou ações concretas que vissem a melhoria da qualidade das águas superficiais da Lagoa e de vida da população que a utiliza como lazer e recreação.

\section{METODOLOGIA}

Os parâmetros mensurados foram oxigênio dissolvido, condutividade elétrica, turbidez, potencial hidrogeniônico e temperaturas do ar e água.

O oxigênio dissolvido - OD é um gás solúvel em água, com concentrações recomendáveis pelo CONAMA Resolução 357 de 17/03/05. Tchobanoglous e Schroeder (1985) afirmam que, devido à sua importância, o OD é amplamente utilizado como principal parâmetro da qualidade de água e serve para determinar o impacto de poluentes sobre corpos d'água, pois é um dos mais importantes fatores no desenvolvimento de qualquer planejamento na gestão de recursos hídricos. Obviamente, o oxigênio dissolvido é o elemento principal no metabolismo dos microrganismos aeróbicos que habitam as águas naturais ou os reatores para tratamento biológico de esgotos, nas águas naturais, o oxigênio é indispensável também para os seres vivos, 
principalmente os peixes. E, cabe salientar que águas poluídas são aquelas que apresentam baixa concentração de O.D.

A condutividade elétrica - CE expressa à capacidade de condução de corrente elétrica de sais dissolvidos e ionizados presentes na água, pode ser utilizada como parâmetro de avaliação de qualidade. Assim a condutividade também fornece uma boa indicação das modificações na composição da água, especialmente na sua concentração mineral, mas não fornece nenhuma indicação das quantidades relativas dos vários componentes.

A turbidez para Pinto (1998) é a alteração da penetração da luz provocada por partículas em suspensão, como bactérias, argilas e silte ou fontes de poluição que lançam materiais finos e outras substâncias na água. Certamente, a presença dessas substâncias provoca a dispersão e a absorção da luz, dando à água aparência nebulosa, esteticamente indesejável e potencialmente perigosa. Enfim, um alto valor de turbidez prejudica criando uma barreira sobre a água, reduzindo a fotossíntese da vegetação enraizada submersa e das algas. Esse desenvolvimento reduzido pode suprimir a produtividade de peixes, além disso, afeta adversamente os usos doméstico, industrial e recreacional da água; estudos técnicos constatam o efeito de proteção física de microorganismos pelas partículas causadoras da turbidez, diminuindo a eficiência de tratamentos.

O PH, potencial hidrogeniônico, é a medida de concentração de íons $\mathrm{H}+$ presentes na solução, é uma das determinações de qualidade de água mais frequentemente executadas, apresentando a acidez ou a basicidade das águas, que podem ter origens em fatores naturais do terreno ou resultantes de poluentes dissolvidos na água. A escala de ph é constituída de uma série de números variando de 0 a 14, os quais denotam vários graus de acidez ou alcalinidade. Valores abaixo de 7 e próximos de zero indicam aumento de acidez, enquanto valores de 7 a 14 indicam aumento da basicidade. A análise do ph será feita através do método eletrométrico (CETESB, 1987).

Com relação às diferentes temperaturas, elas podem gerar camadas d'água com várias densidades, que em si já formam uma barreira física, impedindo que se misturem, e se a energia do vento não for suficiente para misturá-las, o calor não se distribui uniformemente, criando a condição de estabilidade térmica. Quando ocorre este fenômeno, o ecossistema aquático está estratificado termicamente. Os estratos formados freqüentemente estão diferenciados físico, químico e biologicamente. Para Silveira (2004) a temperatura da água é um fator importante na regulação das características físicas e bióticas dos riachos. E, certamente lagos, lagoas e lagunas se assemelham a essa definição.

Com os parâmetros definidos foram escolhidos 13 pontos (Figura 1) estratégicos de coletas de águas dentro e no entorno da Lagoa Maior. 

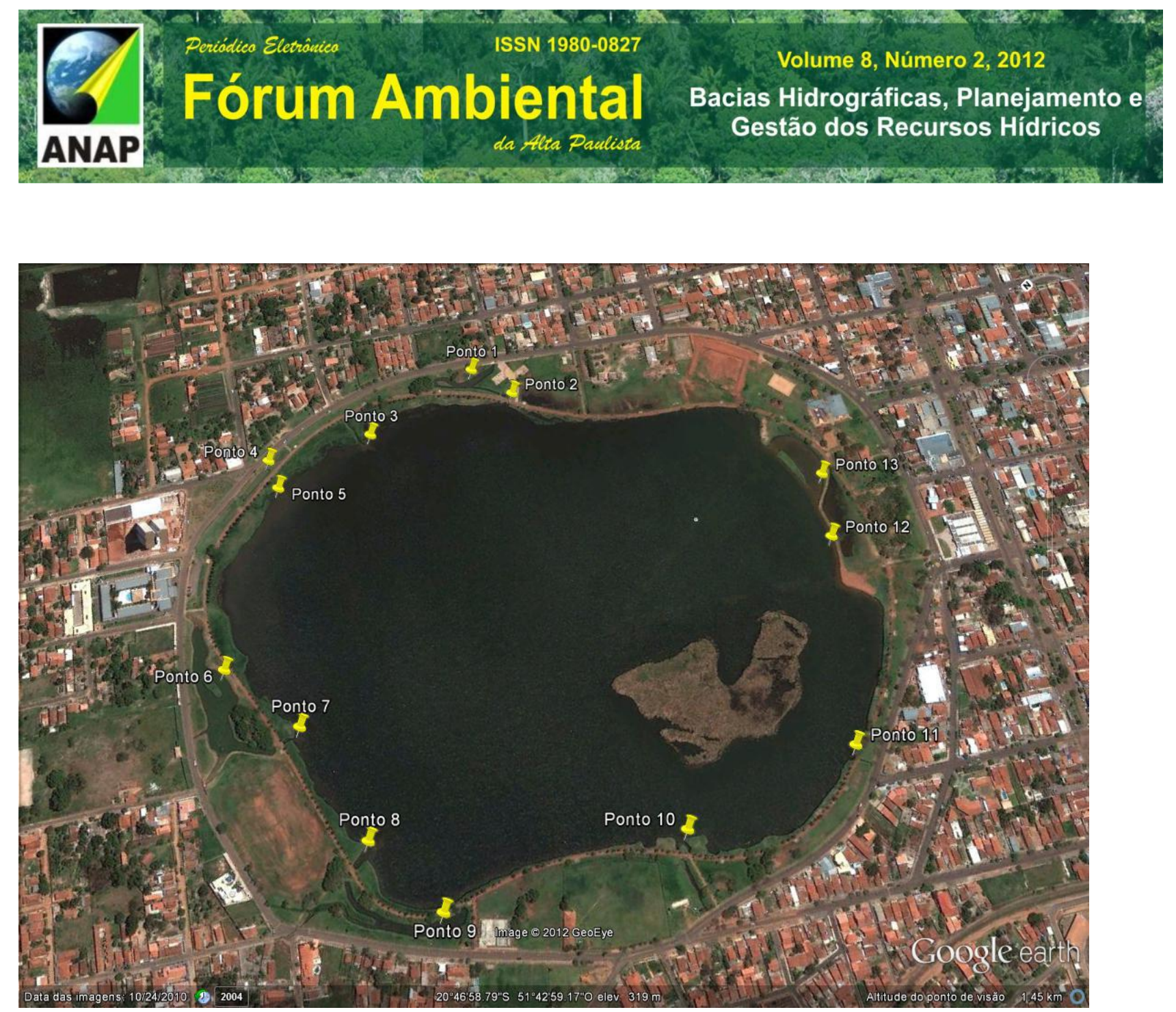

Figura 1 - Vista área da Lagoa Maior e os pontos de monitoramento da qualidade das águas.

Fonte - GeoEye/Google Earth 2012.

Os pontos monitorados foram: 5 caixas de retenções (Pontos 1, 4, 6, 9 e 13); 4 entradas das águas das caixas de retenção para a lagoa (Pontos 2, 5, 7 e 8); 1 entrada do bombeamento da água da Lagoa do Meio para a lagoa Maior (Ponto 3); 1 defronte do parque infantil, área de alimentação das aves (Ponto 12) e; a única saída de água da lagoa, o escoamento para o Côrrego da Onça (Ponto 10). As caixas de retenções são os locais aonde acontece à descarga das águas pluviais, em algumas caixas de retenções existe ainda o afloramento do lençol freático ocasionando o fluxo constante de água e nunca secando, ainda há o escoamento das águas de origem de limpezas das residências e dos comércios no entorno desse grandioso patrimônio natural.

Após a geração dos resultados em campo deu início a avaliação da qualidade das águas superficiais da Lagoa Maior. Logo, para a avaliação da qualidade das águas utilizou-se das classes de enquadramento do Conselho Nacional do Meio Ambiente, resolução 357/05 para água doce (Tabela 1), que estabelecem limites para uso da água. O CONAMA em sua resolução determinou 5 
diferentes classes, são elas: Especial, I, II, III e IV. Classes que são delimitadas pelo valor de cada parâmetro coletado. Não foi utilizada a resolução 430 de 2011, visto que oficialmente não se encontra emissário de efluente que atinge a lagoa Maior.

Tabela 1 - Limites dos Parâmetros Analisados para Enquadramento nas Classes das Águas Doces no Brasil.

\begin{tabular}{|c|c|}
\hline Classes & Limites para o Enquadramento \\
\hline Especial & $\begin{array}{l}\text { Nas águas de classe especial deverão ser mantidas as condições naturais do corpo de água. } \\
\text { OD }+10,0 \mathrm{mg} / \mathrm{l} \\
\text { pH } 6,0 \text { a } 9,0 \\
\text { Turbidez até } 20 \text { NTU } \\
\text { Condutividade Elétrica até } 50 \mathrm{um}\end{array}$ \\
\hline $\mathbf{I}$ & $\begin{array}{l}\text { OD } 10 \text { a } 6 \mathrm{mg} / \mathrm{l} \\
\text { pH } 6,0 \text { a } 9,0 \\
\text { Turbidez } 20 \text { até } 40 \mathrm{NTU} \\
\text { Condutividade Elétrica } 50 \text { até } 75 \text { um }\end{array}$ \\
\hline II & $\begin{array}{l}\text { OD } 6 \text { a } 5 \mathrm{mg} / \mathrm{l} \\
\text { pH } 6,0 \text { a } 9,0 \\
\text { Turbidez } 40 \text { até } 70 \text { NTU } \\
\text { Condutividade Elétrica } 75 \text { até } 100 \text { um }\end{array}$ \\
\hline III & $\begin{array}{l}\text { OD } 5 \text { a } 4 \mathrm{mg} / \mathrm{l} \\
\text { pH } 6,0 \text { a } 9,0 \\
\text { Turbidez } 70 \text { até } 100 \mathrm{NTU} \\
\text { Condutividade Elétrica } 100 \text { até } 150 \text { um }\end{array}$ \\
\hline IV & $\begin{array}{l}\text { OD }-4 \mathrm{mg} / \mathrm{l} \\
\text { pH } 6,0 \text { a } 9,0 \\
\text { Turbidez acima de } 100 \mathrm{NTU} \\
\text { Condutividade Elétrica }+150 \text { um }\end{array}$ \\
\hline
\end{tabular}

Elaboração - Pinto et. al. (2008) adaptado da Resolução №. 357/05 do CONAMA.

Contudo, é feito a aferição de cada parâmetro utilizado e com isso a delimitação de enquadramento por classes. Cada classe recebe do CONAMA recomendações (Tabela 2) para as principais práticas de uso de suas águas, recomendações essas que são essenciais para a vida saudável.

Tabela 2 - Principais Classes de Limitações de Uso das Águas Doces no Brasil.

\begin{tabular}{c|l}
\hline Classes & Principais Usos \\
\hline Especial & $\begin{array}{l}\text { Consumo humano com desinfecção; Preservação de equilíbrio natural das comunidades } \\
\text { aquáticas; Preservação dos ambientes aquáticos em unidades de conservação de proteção } \\
\text { integral. }\end{array}$ \\
\hline \multirow{1}{*}{$\begin{array}{l}\text { Consumo humano, após tratamento simplificado; Proteção das comunidades aquáticas; } \\
\text { Recreação de contato primário (natação, esqui aquático e mergulho) Resolução CONAMA n. } \\
274, \text { de 2000; Irrigação de hortaliças que são consumidas cruas e de frutas que se } \\
\text { desenvolvam rentes ao solo e que sejam ingeridas sem remoção de películas e à proteção das } \\
\text { comunidades aquáticas em Terras Indígenas. }\end{array}$} \\
\hline $\begin{array}{l}\text { Abastecimento para consumo humano, após tratamento convencional, à proteção das } \\
\text { comunidades aquáticas, à recreação de contato primário, tais como natação, esqui aquático e e }\end{array}$ \\
\hline
\end{tabular}




\begin{tabular}{c|l}
\hline II & $\begin{array}{l}\text { mergulho, Resolução CONAMA n. 274, de 2000, à irrigação de hortaliças, plantas frutíferas e de } \\
\text { parques, jardins, campos de esporte e lazer, com os quais o público possa vir a ter contato } \\
\text { direto e à aqüicultura e à atividade de pesca. }\end{array}$ \\
\hline III & $\begin{array}{l}\text { Abastecimento para consumo humano, após tratamento convencional ou avançado, à irrigação } \\
\text { de culturas arbóreas, cerealíferas e forrageiras, à pesca amadora, à recreação de contato } \\
\text { secundário e à dessedentação de animais. }\end{array}$ \\
\hline IV & Navegação e à harmonia paisagística \\
\hline
\end{tabular}

Fonte - Resolução №. 357 do CONAMA de 17/03/2005.

\section{RESULTADOS E DISCUSSÕES}

Utilizando os aparelhos específicos para a coleta, foram obtidos os seguintes enquadramentos na Tabela 3.

Tabela 3 - Enquadramento dos pontos e estações, e médias por ponto e mensal das águas superficiais da Lagoa Maior, Três Lagoas/MS, no período de Maio a Dezembro/2011 e de Fevereiro a Abril/2012.

\begin{tabular}{|c|c|c|c|c|c|c|c|c|c|c|c|}
\hline \multirow[b]{2}{*}{ Pontos } & \multicolumn{2}{|c|}{ Outono } & \multicolumn{2}{|c|}{ Inverno } & \multicolumn{3}{|c|}{ Primavera } & \multicolumn{3}{|c|}{ Verão } & \multirow[b]{2}{*}{ Média por Ponto } \\
\hline & Mai. & Jun. & Ago. & Set. & Out. & Nov. & Dez. & Fev. & Mar. & Abr. & \\
\hline 1 & ॥II & ॥ & IV & IV & ॥ & ॥II & II & ॥ & ॥II & IV & 111 \\
\hline 2 & \|\| & ॥II & ॥I & \|\| & ॥ & III & II & ॥I & ॥I & III & 111 \\
\hline 3 & III & III & IV & IV & III & III & \|\| & \|\| & IV & IV & IV \\
\hline 4 & IV & IV & IV & ॥ा॥ & III & IV & IV & ॥II & IV & IV & IV \\
\hline 5 & IV & II & IV & IV & ॥ & IV & III & ॥II & III & IV & IV \\
\hline 6 & $\|$ & III & \|\| & \|\| & $\|$ & IV & \|\| & \|\| & ॥I & \|\| & 111 \\
\hline 7 & IV & II & ॥ & \|\| & IV & III & ॥ & II & III & IV & 111 \\
\hline 8 & III & $\|$ & ॥ & IV & II & III & 1 & 1 & 1 & \|\| & \\
\hline 9 & IV & IV & III & IV & III & IV & IV & III & IV & IV & IV \\
\hline 10 & 1 & ॥I & $\|$ & III & II & III & 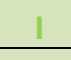 & II & $\|$ & II & \\
\hline 11 & ॥II & ॥I & ॥I & ॥II & II & 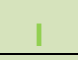 & 1 & II & 1 & ॥ & \\
\hline 12 & ॥ & ॥ & ॥ & II & ॥ & 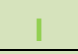 & 1 & ॥ & 1 & ॥ा॥ & \\
\hline 13 & II & II & ॥ & ॥ & III & 1 & ॥ & ॥ & 1 & III & \\
\hline Média Mensal & 111 & 111 & 11 & 111 & & 111 & 111 & 111 & III & IV & \\
\hline
\end{tabular}

O enquadramento geral mensal, utilizando-se dos valores mais restritivos, ou seja, a de pior qualidade oscilou na Lagoa entre as classes III e IV, que preconiza: na classe III sua utilização para o abastecimento para consumo humano, após tratamento convencional ou avançado, à irrigação de culturas arbóreas, cerealíferas e forrageiras, à pesca amadora, à recreação de contato 
secundário e à dessedentação de animais e na classe IV, apenas para a navegação e à harmonia paisagística.

Pensando na Lagoa como parte da drenagem da bacia do Córrego da Onça (o principal curso d água urbano), e levando-se em consideração os valores da estação 10 , onde a água da Lagoa escoa para o mais importante rio urbano que em sua foz encontra o Rio Paraná, o enquadramento ficou na classe II do CONAMA. Tal enquadramento, permite que suas águas possam ser utilizadas para consumo humano após tratamento simplificado, proteção das comunidades aquáticas, recreação de contato primário (natação, esqui aquático e mergulho). O problema é que ao longo de seu percurso urbano, o Córrego da Onça é canalizado, recebendo esgoto clandestino via galerias pluviais e na Vila Zucão, quando volta a correr a céu aberto, recebe grande deposição de resíduos sólidos e plumas de contaminações de fossas rudimentares, contaminando consideravelmente suas águas.

As estações mostraram que independentemente no inverno seco ou verão chuvoso, a qualidade das águas superficiais praticamente não possui alteração. Inclusive o mês de Abril de 2012, que é a transição do verão para o outono foi o mês com a pior qualidade, ficando na classe IV.

As caixas de retenção, com exceção do ponto 1, que seca e desempenha sua função, as demais não secam mesmo nas estiagens mais pronunciadas, como foi o inverno de 2011, com apenas 18,6 mm e o verão chuvoso de 2012, com 378 mm (AGRAER, 2012). Não secam, pois recebem contribuição do freático, mantendo-se sempre cheias e emitindo constantes plumas de contaminação para a Lagoa, sem nenhum tratamento prévio.

Considerando os resultados obtidos mais restritivos, em especial das caixas de retenção, como é o caso da estação 9, que devido à elevada turbidez de suas águas e de sua condutividade elétrica, tendo grande limitação de uso dessas águas que lançadas a Lagoa Maior a contaminam.

Portanto, como trata-se de água destinada ao lazer e a recreação, ou fraciona-se as margens da Lagoa Maior e se estipula balneabilidade por trecho ou se considera como um corpo hídrico único e se utiliza o valor mais restritivo.

Valendo relembrar, que na estação seca do inverno, com menor entrada de água pluvial, as concentrações de OD e Condutividade Elétrica, tenderão a se elevar. Como o monitoramento com os parâmetros utilizados são de baixo custo e de fácil realização, propõem-se que sejam realizados mensalmente, para subsidiarem ações públicas sérias, em prol da saúde da coletividade urbana de Três Lagoas, que tem na Lagoa Maior um dos seus principais pontos de lazer e recreação.

\section{REFERÊNCIAS}

VIII Fórum Ambiental da Alta Paulista, v. 8, n.2, 2012, p. 151-159. 
AGRAER, Agência de Desenvolvimento Agrário e Extensão Rural. Dados Climatológicos do Município de Três Lagoas 2011 e 2012. 2012.

BRASIL. Conselho Nacional do Meio Ambiente - CONAMA Resolução 357/2005: Enquadramento dos Corpos Hídricos Superficiais no Brasil. Governo Federal, Brasilia. Publicada no DOU no 53, de 18 de março de 2005, Seção 1, p.58 - 63.

CETESB. Companhia de Tecnologia de Saneamento Básico. Guia de coleta e preservação de amostras de água. São Paulo, 1987. 150p. (Séries guias)

GOOGLE. Imagem aérea do Satélite GeoEye. In: Google Earth. 2012.

MOITTA, R.; CUDO, K. J. Aspectos gerais da qualidade da água no Brasil. In: Reunião Técnica sobre Qualidade da Água para Consumo Humano e Saúde no Brasil. Brasília, 1991. p.1 - 6.

PEREIRA, L. C.; TOCCHETTO, M. R. L. Qualidade Ambiental e Ecoeficiência: nova postura para industria de alto impacto. 2004. Disponível em: $<$ http://ambientes.ambientebrasil.com.br/gestao/artigos/qualidade ambiental e ecoeficiencia\%3A nova postura para industrias de alto impacto. html>. Acesso em jun 2012.

PINTO, A. L. Saneamento Básico e suas Implicações na Qualidade das Águas Subterrâneas da Cidade de Anastácio (MS). 1998. 175p. Tese (Doutorado e Geociências) - Universidade Estadual Paulista/Instituto de Geociências e Ciências Exatas, Rio Claro, 1998.

SILVEIRA, M. P. Aplicação do biomonitoramento para avaliação da qualidade da água em rios. Embrapa Meio Ambiente. Jaguariúna, 2004.

TCHOBANOGLOUS, G.; SCHROEDER, E. D. Water quality - characteristics, modelling, modfication. Addison-Wesley Publ. Co., EUA, 1985

TUNDISI, J. G. Liminologia do século XXI: perspectivas e desafios. São Carlos: Suprema Gráfica e Editora, 1999. 24p. 